\title{
Impacted Maxillary Canines, Premolar and Central Incisor - Surgical Exposure and Orthodontic management
}

\author{
Hossain MZ1 BDS, PhD, Mamun MSA², BDS and Haque ${ }^{3}$, BDS, MS
}

\begin{abstract}
The importance of maxillary canine impaction is that it may compromise dental health , particularly because a small but significant proportion of impacted canine is associated with the resorption of the roots of neighbouring teeth. A few cases of impacted upper canines, premolar and central incisors of different ages are presented. Although the best treatment alternative for impacted teeth is extraction, the same cannot be directly applied to canines and central incsor especially. Since canines present with them a high demand on aesthetic and functional requirements. Thus, alignment of impacted canines into the arch is the best treatment approach. The purpose of this study is to evaluate the impacted maxillary canines that were surgically exposed, followed by orthodontic alignment into occlusion.
\end{abstract}

Key Words : Impaction, Surgical exposure, Orthodontic alignment (Ban J Orthod \& Dentofac Orthop, October 2010; Vol1, No. 1, 24-26)

\section{INTRODUCTION}

Treatment of orthodontic patients entails the management of a constantly changing occlusion from the early mixed dentition to the permanent dentition. In a majority of patients, transition from mixed to permanent dentition occurs uneventfully, without tooth impaction or lack of tooth eruption. However, in a few patients canine impaction may occur as a result of a deviation from the normal sequence of development. Permanent canines are the foundation of an esthetic smile and functional occlusion. ${ }^{1}$ Any factor that interferes with their normal development and eruption can lead to impaction and serious consequences.

The impaction of the tooth is a retardation of halt in the normal process of eruption. According to Kuftinee and Shapira, ${ }^{2}$ impaction is a condition in which a tooth is embedded in the alveolus so that its eruption is impeded and it is locked in position by bone or by adjacent teeth.

In current perspective, an impacted tooth is one "whose eruption is considerably delayed, and for which there is clinical or radiographic evidence that further eruption may not take place."

In simple words, an impacted tooth is one that fails to erupt into a normal functional position past its root formation, which may be attributable to physical impedance (other tooth or surrounding soft or hard tissue), ankylosis, a systemic cause or primary failure of eruption.

The impaction of maxillary permanent canine is a frequently encountered clinical problem. The diagnosis and treatment planning of this problem usually requires the expertise cooperation of the Oral Surgeon as well as the Orthodontist.

An overview of the incidence \& sequelae, as well as as the surgical and periodontal \& Orthodontic consideration in the management of impacted canine is presented.

\section{Incidence of canine impaction}

Dachi \& Howell 3 reported that the incidence of maxillary canine impaction is $0.92 \%$, whereas Thailander $\mathrm{B}$, Jacobson $\mathrm{SO}^{4}$ estimated prevalence of canine impaction in 7-13 year old children to be $2.2 \%$. Ericson \& kurol5,6,7 estimated the incidence at $1.17 \%$. Impactions are twice as common in females $(1.17 \%)$ as in males (0.51\%). Of all patients with maxillary impacted canines, it is estimated that $8 \%$ have bilateral impactions. The incidence of mandibular canine impaction is $0.35 \%$. In Bangladesh the incidence of impacted maxillary canine is $2.76 \%{ }^{8}$

Since maxillary canines are impacted more frequently, the emphasis of this presentation will be on their management and also management of Incisors.

\section{Developmental Consideration}

Anatomically maxillary canines have the longest period of development, as well as the longest and most tortous course to travel from the point of formation, lateral to the piriform fossa, until they reach their final destination. During the course of development, the crown of the permanent canines are intimately related to the roots of lateral incisors. Many authors have cautioned against the early correction of the flared \& distally tipped lateral incisors for fear of either impacting the canines or resorbing the roots of the lateral incisors.

\section{Management Protocol}

Management of Palatally Impacted Canine:

There are many surgical methods for exposing the impacted canine \& bringing it to the line of occlusion. Two of the most commonly used methods are

1. Surgical exposure, facilitating natural eruption. This method is most useful when the canine has a correct axial inclination

${ }^{1}$ Professor \& Head, Dept of Orthodontics and Dentofacial Orthopedics, Dhaka Dental College \& Hospital, Mirpur -14, Dhaka 1206. ${ }^{2}$ FCPS, Part II Trainee, Dept. of Orthodontics and Dentofacial Orthopedics, Dhaka Dental College. ${ }^{3}$ Assistant Professor, Dept. of Conservative Dentistry, Dhaka Dental College \& Hospital 
and does not require uprighting during its eruption. The progress of canine eruption can be monitored with the $\mathrm{X}$ ray using the adjacent tooth as a reference point.

2. Surgical exposure with placement of auxiliary attachment followed by orthodontic traction. Two approaches are generally recommended in regard to timing of placing the attachment:

I. First, the canine is surgically uncovered \& the area is packed with surgical dressing to avoid the filling in of tissue around the tooth. After wound healing, within 3-8 weeks, the pack is removed, and the attachment is placed.

II. Second method: is a one step approach. The bracket is bonded at the time of surgical exposure.

Earlier methods of uncovering impacted canine advocated radical bone removal to expose the crown of the impacted tooth so as to remove all bony obstacles and to provide an easier path for tooth movement. Cemento enamel junction (CEJ) exposure should be avoided.

As stated earlier, labial impaction of the maxillary canine is less frequent than palatal impaction and is often caused by insufficient arch length. Thus the canine is often positioned high in the alveolar bone. In older patients, traction is indicated following surgical exposure.

In the presenting cases, a one step technique was applied for maxillary canines, premolar and central incisor. The bracket was bonded at the time of surgical exposure, followed by orthodontic traction and alignment in the occlusion.

\section{RADIOLOGICAL EXAMINATION}

The commonly used X-rays include an OPG of maxilla and mandible, occlusal view and IOPA films.

\section{CASE REPORT AND TREATMENT PROGRESSION}

A 25 years old adult (Case :1), 22 years old young adult (Case : 2), 14 years old young girl (Case:3) and 10 years old growing girl (Case; 4) were referred by different general Dental practitioner for non-eruption of both left permanent maxillary cuspid and bicuspid, left upper cuspid, left upper cuspid and left upper central incisor respectively. Occlusal X-ray and OPG Xray revealed presence of all above mentioned impacted teeth. The conventional flap was used to locate both teeth. Molars were banded and all teeth including impacted teeth were bonded with edgewise brackets, which exposed out of the incision. Gentle orthodontic traction was given by ligating wire followed by power chain for all the cases till they were aligned into occlusion. The guidance of impacted cuspid, bicuspid and central incisor into occlusion lead to better functional occlusion in individual cases.

\section{Case: I}

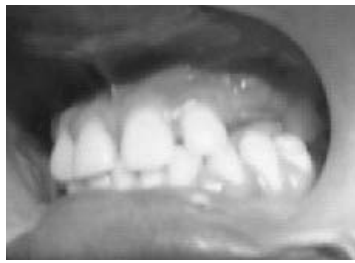

Intraoral photo shows

impacted upper 3,4

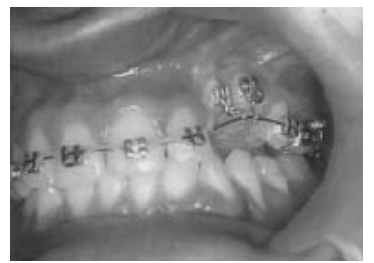

Edge-wise appliance with Orthodontic traction of upper left 3,4

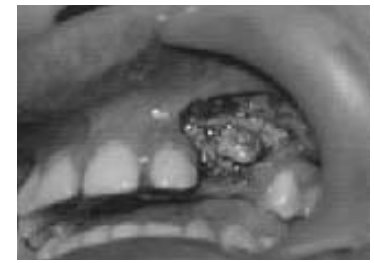
orthodontic traction

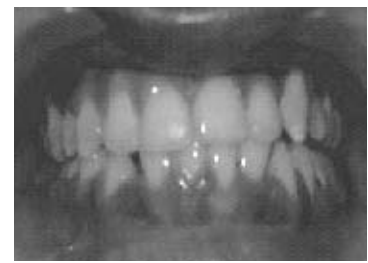

After complete alignment of impacted upper left 3,4
Surgical exposure of 3,4 for

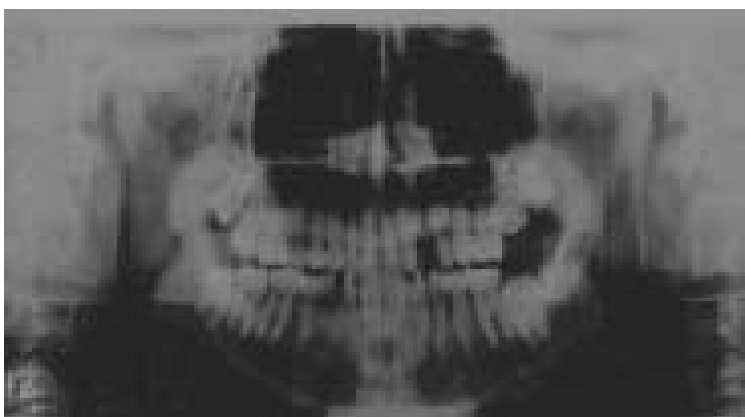

OPG X-ray before treatment showing Impacted upper left 3 and 4 with retained $\mathrm{C}$ and $\mathrm{D}$

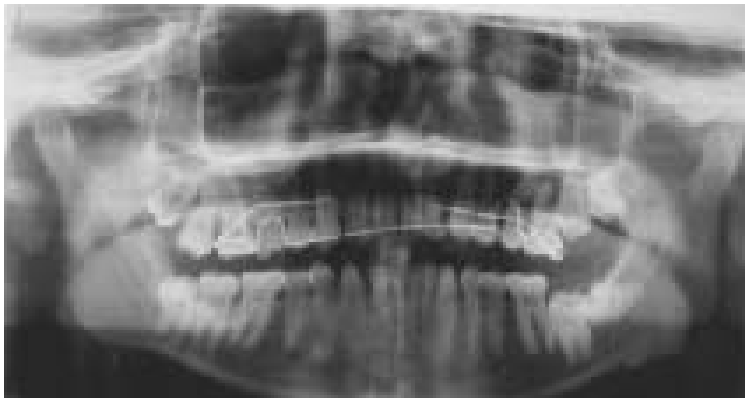

After treatment: showing alignment of upper left 3 and 4 after orthodontic traction 


\section{Case: 2( Impacted upper left canine)}

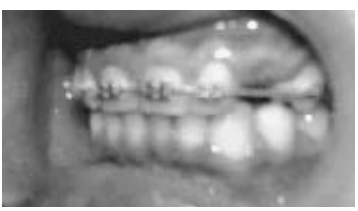

Impacted Canine

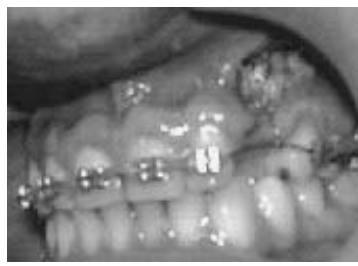

Edge-wise appliance with Orthodontic traction of upper left 3
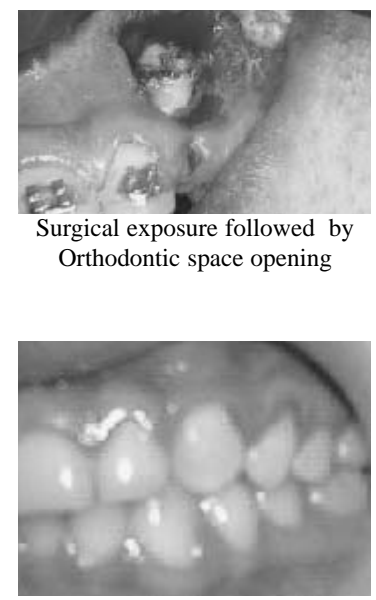

After Orthodontic Alignment

\section{Case : 4 ( Imacted upper left central)}

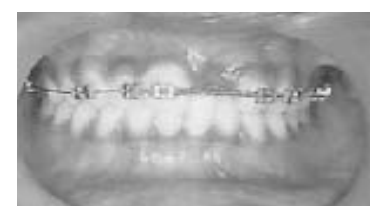

Edge wise appliance with Coil spring to open space for impacted left central

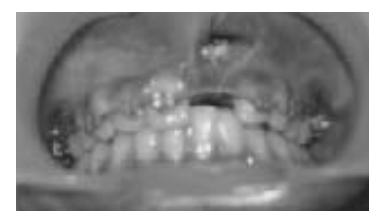

Surgical exposure followed by orthodontic traction

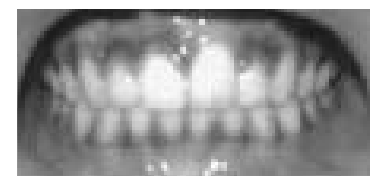

After complete alignment \& debonding

\section{CONCLUSION}

Management of impacted teeth requires careful approach for treatment of malocclusion. It also necessitates that prognosis is to be evaluated before hand after thorough diagnosis. The other factors to govern the orthodontic management of impacted teeth are oral hygiene, status of oral health, existing malocclusion, patient's willingness to undergo treatment including socioeconomic considerations. The treatment result of these cases helped the aesthetic and functional need of the individuals. In all of the cases, gingival attachment after orthodontic traction were well maintained.

\section{REFERENCES}

1. Bass T. Observation on the misplaced upper canine tooth. Dent Pract Dent Rec 1967;18:25-33. (!)

2. Kuftinec MM, Shapira Y, The impacted maxillary canine: I. Review of concepts. ASDDC J Dent Child 1995; 62 (5): 317-24.

3. Dachi SF, Howell FV. A survey of 3874 routine full-mouth radiagraphs: II. A study of impacted teeth. Oral Surg Oral Med Oral Pathol 1961; 14: 1165-69.

4. Thilander B, Jacobson SO. Local factors in impaction of maxillary canine. Acta odontol Scand 1968: 26:145-68.

5. Ericson S, Kurol J. Early treatment of palatally erupting maxillary canines by extraction of the primary canines. Eur J Orthod 1988; 10: 283-95.

6. Ericson D, Kurol J. CT diagnosis of the ectopically erupting maxillary canines- a case report. Eur J Orthod 1988; 10:115-21

7. Ericson S, Kurol J. Resorption of maxillary lateral incisor caused by ectopic eruption of canines: a clinical and radiographic analysis of predisposing factors. Am J Othod Dentofacial Orthop 1988; 94(6): 503-13.

8. Alam M. Mahbub, Incidence of Impacted permanent canine \& its Orthodontic management, approved by Bangladesh College of Physician \& Surgeons, 2009.

\section{Correspondence}

Dr. Zakir Hossain, BDS, PhD

Professor \& Head, Dept of Orthodontics and Dentofacial Orthopedics, Dhaka Dental College \& Hospital, Mirpur -14, Dhaka 1206

E-mail: hossainzortho@yahoo.com, Web: www.orthodentalcare.com 